\title{
Anaerobic digestion of cattle manure: effect of phase-separation
}

\author{
V. Yilmaz \& G. N. Demirer ${ }^{2}$ \\ ${ }^{I}$ Department of Environmental Engineering, Akdeniz University, Turkey \\ ${ }^{2}$ Department of Environmental Engineering, \\ Middle East Technical University, Turkey
}

\begin{abstract}
Various aspects of anaerobic digestion (AD) technology have been the focus of research in recent years. Shortening the digestion time with enhanced process efficiency is one of the integral concerns in AD technology. This study was conducted to investigate the feasibility of a two-phase anaerobic treatment system for unscreened dairy manure. Hydraulic retention time (HRT) and organic loading rate (OLR) in the hydrolytic reactor are varied in order to evaluate the effect of these factors. The results showed that an optimum HRT and OLR of 2 days and 15 g.VS/L.day, respectively, yielded maximum acidification. The separation of acidogenic and methanogenic phases of digestion resulted in a significant increase in methane production rate in the methane reactor. The methane yields were found to be 313 and $221 \mathrm{~mL} \mathrm{CH}_{4} / \mathrm{g}$.VS loaded in two-phase and one-phase systems at $35^{\circ} \mathrm{C}$, respectively.
\end{abstract}

Keywords: anaerobic digestion, dairy manure, two-phase, methane.

\section{Introduction}

With the rapid depletion of conventional energy sources, the need to find alternative, but preferably renewable, sources of energy is becoming increasingly acute. Through anaerobic digestion of biomass, including animal wastes, useful energy can be obtained [20]. Biogas plants are expected to be an effective solution to the manure management problem providing benefits such as energy saving, environmental protection and reduced $\mathrm{CO}_{2}$ emissions.

Anaerobic digestion of organic matter became more and more attractive in the recent past because new reactor designs significantly improved the reactor 
performance [29]. Studies have shown that anaerobic treatment is a stable process under proper operation. But parameters such as process configuration, temperature, biomass, $\mathrm{pH}$, nutrient, and substrate must be carefully scrutinised in order to make successful anaerobic treatment. Many process configurations have been investigated. An improvement in the efficiency of anaerobic digestion can be brought about by either digester design modification or advanced operating techniques [16].

On farms anaerobic digestion of animal manure is an attractive technique for both energy and organic fertilizer production. Literature on manure digestion is mainly focused on liquid manure (i.e. total solids $<100 \mathrm{~g} / \mathrm{l}$ ) digestion. Nevertheless many farms, especially smaller ones, throughout the world, still produce solid manure. For on-farm application the digestion system should be as simple as possible to operate and in agreement with the on-farm practice [6].

Conventional anaerobic digestion is proceeded in a single reactor where acidogenesis and methanogenesis both occur. Acidogenesis and methanogenesis are respectively proceeded in two separate reactors and each phase is in the best environmental conditions [16]. This phase separation can be achieved by maintaining a very short HRT in the acid phase reactor. The effluent from the first, acid-forming, phase is then used as the substrate for the methane-phase reactor [19].

One relevant feature of the two-phase approach is that when a high solid containing waste is introduced to the first phase it is liquefied along with acidification. This translates into less liquid addition and, thus, less energy requirements for heating, storing and spreading for two-phase $\mathrm{AD}$ systems. The results of several studies $[1,3,7,10,11,15,17,21,25]$. have clearly demonstrated the applicability and efficiency of two-phase AD for high solids containing wastes.

The advantages of two-phase operation have been extensively documented [9, 22]. Prospects for the phased anaerobic treatment of wastewater are promising. With the variety of reactor designs available and the amenability of reactors to modification, existing treatment systems may be replaced or upgraded as required to achieve increased stability, higher loading capacities and greater process efficiencies than are possible using single-stage systems [16]. Even though several aspects of two phase configuration including liquefaction might be very significant for efficient $\mathrm{AD}$ of dairy manure, its application has been limited to screened dairy manure only $[5,20,26]$.

This work aimed to evaluate the feasibility of a two-phase anaerobic treatment system for unscreened dairy manure. The specific objective was to compare the effects of different HRT and OLR for optimum acidification.

\section{Materials and methods}

Wet manure was collected from a private dairy around Gölbaşı, Ankara, and stored at $4{ }^{\circ} \mathrm{C}$ prior to use. The composition of the dairy manure used in this study had the following characteristics; total solids (TS), $20.1 \pm 1.7 \%$, volatile solids (VS), $67 \pm 4.6 \%$ of TS and density, $1042 \pm 0.04 \mathrm{~g} / \mathrm{L}$. The raw manure was 
diluted with water to decrease the solids content to achieve slurry with 3.5 , and $15 \mathrm{~g} . \mathrm{VS} / \mathrm{L}$. The relationship between chemical oxygen demand (COD) and VS of this manure was found as 1.04 .

The mixed anaerobic culture used as seed was obtained from the anaerobic sludge digesters at the Ankara wastewater treatment plant, which has a solids retention time (SRT) of 14 days. The mixed anaerobic culture was concentrated by settling before being used as inoculum. The volatile suspended solids (VSS) concentration of the concentrated seed cultures used was $23930 \pm 3162 \mathrm{mg} / \mathrm{L}$.

\subsection{Experimental set-up}

In the first part of the study, the optimum retention time and organic loading rate (OLR) values leading to maximum acidification and VS reduction were investigated. Thus, nine daily-fed continuously-mixed acidogenic anaerobic reactors with no recycle were operated as duplicates. The experiments were performed in $250 \mathrm{~mL}$ serum bottles capped with rubber stoppers. Reactor operation involved daily feeding of wet dairy manure and wasting of the corresponding reactor contents as indicated in table 1. Solids and hydraulic retention times (SRT/HRT) applied to each reactor was the same since no recycle of the effluent was practiced. Initially, each reactor was seeded with $100 \mathrm{~mL}$ of concentrated anaerobic seed cultures. The next day dairy manure $(25 \mathrm{~mL}$ to reactors $1-3,50 \mathrm{~mL}$ to reactors $4-6$, and $80 \mathrm{~mL}$ to reactors $7-9$ ) were added to each reactor. Daily feeding and wasting were conducted as seen in table 1 . The reactors were flushed with $\mathrm{N}_{2} / \mathrm{CO}_{2}$ gas mixture for $3 \mathrm{~min}$ and maintained in an incubator shaker at $35 \pm 1^{\circ} \mathrm{C}$ and $165 \mathrm{rpm}$.

Table 1: $\quad$ Daily feeding and wasting used for acidogenic reactors.

\begin{tabular}{cccc}
\hline Reactor & $\begin{array}{c}\text { SRT } \\
\text { (days) }\end{array}$ & $\begin{array}{c}\text { OLR } \\
\text { (g.VS/L day) }\end{array}$ & $\begin{array}{c}\text { Volume of } \\
\text { feeding/wasting (ml) }\end{array}$ \\
\hline 1 & 4 & 5 & 25 \\
2 & 4 & 10 & 25 \\
3 & 4 & 15 & 25 \\
4 & 2 & 5 & 50 \\
5 & 2 & 10 & 50 \\
6 & 2 & 15 & 50 \\
7 & 1.25 & 5 & 80 \\
8 & 1.25 & 10 & 80 \\
9 & 1.25 & 15 & 80 \\
\hline
\end{tabular}

The one-phase conventional configuration (R1) was run as the control for the two-phase configuration (R2). The effective volumes of R1, R21, and R22 were 1000,400 , and $1000 \mathrm{~mL}$, respectively. The two-phase configuration contained R21 and R22 as the first (acidogenic) and second (methanogenic) phases.

The SRT/HRT values of R1, R21, R22 and the overall two-phase configuration were $20,2,8.6$, and 10.6 days, respectively. The gas production in R1, R21 and R22 were monitored by a water replacement device was used to 
monitor the gas production. One set of reactors were maintained at $25^{\circ} \mathrm{C}$ in a temperature-controlled water bath and the others at $35^{\circ} \mathrm{C}( \pm 2)$ in a controlled room, and all reactors were shaken manually once daily after conducting the gas production measurement. Solids and hydraulic retention times (SRT/HRT) applied to each reactor was the same since no recycle of the effluent was practiced. R1, R21, and R22 were seeded with 500, 200, and $500 \mathrm{~mL}$ of mixed anaerobic seed culture. The performance of the reactors was monitored by measuring biogas production and soluble COD, VS, volatile fatty acid (VFA), and $\mathrm{pH}$.

\subsection{Analytical methods}

The $\mathrm{pH}$, daily gas production, total solids, volatile solids, methane percentage, total volatile fatty acids (TVFA) and effluent soluble COD (sCOD) were monitored in each reactor. $\mathrm{pH}$, TS, VS analysis was performed using Standard Methods [2]. sCOD was measured using Hach COD vials according to the EPA approved digestion method [12]. Accordingly, after $2 \mathrm{~h}$ digestion, sCOD of sample were directly read using Hach 45 600-02 spectrophotometer (Hach Co. Loveland, Co., USA). TVFA and biogas composition were measured by gas chromatography as described by Yilmaz and Demirer [32].

\section{Results and discussion}

Nine acidogenic anaerobic reactors were operated for 57 days to determine the optimum SRT and OLR values resulting in maximum acidification and in turn VS reduction. Three different OLRs (5, 10 and 15 g.VS/L.day) were applied to the reactors. For each OLR value, three SRTs (1.25, 2 and 4 days) were studied (table 1). The results are given in fig. 1 in terms of the change in the operating parameters ( $\mathrm{pH}, \mathrm{TVFA}, \mathrm{VS}$, cumulative gas production (CGP), methane content and SCOD) with respect to the combination of OLR and SRT values. Figure 1 does not include the data points within the first "3xSRT" days (12 days for R1R3, 6 days for R4-R6, and 4 days for R7-R9) which are the theoretical time to reach to steady-state conditions in a continuous reactor.

As seen in fig. 1.a, $\mathrm{pH}$ drop was inversely proportional with the increase in the SRT for each OLR studied. Similarly, for each SRT studied, as the OLR increased, $\mathrm{pH}$ decreased. It was observed that the extent of $\mathrm{pH}$ drop increased with the increase in the OLR being smallest for the lowest OLR of 5 g.VS/L.day. Besides, it should be noted that the extent of $\mathrm{pH}$ drop was also affected by the SRT. For all the OLRs studied, the extent of $\mathrm{pH}$ drop for the SRT increase from 1.25 to 2 days was greater than that observed for SRT of 2 to 4 days. It is a well known fact that low retention times and high loading rates lead to higher acidification in two-phase systems. However, as seen in fig. 1.a, average $\mathrm{pH}$ values observed in the reactors were within 6.2-6.6 and the extent of $\mathrm{pH}$ drops was lower relative to acidification of other high solid substrates such as organic fraction of municipal solid wastes. Han et al., [13] operated the MUSTAC (multi-step sequential batch two-phase anaerobic composting) process to recover 
methane and composted material from food waste, where the $\mathrm{pH}$ ranged between 6.5 and 7.0 during acidogenic fermentation step. In another research, Kübler and Schertler [18] demonstrated that favourable pH condition was 6.7 in the threephase anaerobic degradation of solid waste. Verrier et al., [27] stated that both mesophilic and thermophilic liquefaction and acidogenesis of vegetable solid wastes were found to be maximal when the $\mathrm{pH}$ was maintained at approximately 6.5 in the hydrolysis reactor. The relatively high $\mathrm{pH}$ values observed in our study can be explained by the alkalinity generated by the anaerobic biodegradation of nitrogenous organic compounds contained in the dairy manure used in this study $[8,30]$. The similar self-buffering capacity of the manure was also observed in other acidification studies $[4,5]$.
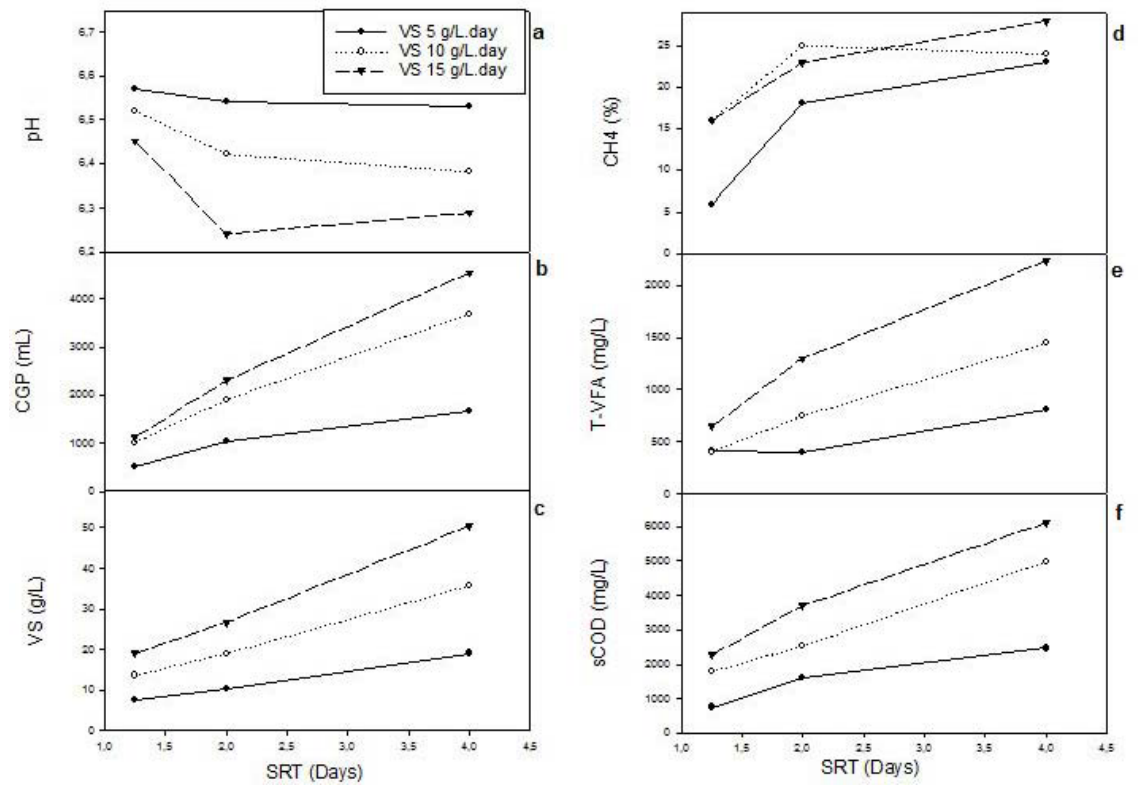

Figure 1: $\mathrm{pH}, \mathrm{T}-\mathrm{VFA}, \mathrm{VS}, \mathrm{CH}_{4}$ percentage, biogas production, and sCOD values observed during the first part of the experiment.

As expected, the increase in the OLR resulted in the increase in the TVFA production (fig. 1.b). In addition, the extent of TVFA production for the SRT increase from 1.25 to 2 days was greater than that observed for SRT increase from 2 to 4 days especially for OLRs of 10 and $15 \mathrm{~g}$.VS/L.day. This observation was also verified by the extent of $\mathrm{pH}$ drop (being greater for SRT increase from 1.25 to 2 days). These TVFA production trends for all reactors coincided with the SCOD productions (fig. 1.c) which increased with the increased OLR and SRT. 
The effect of SRT and OLR on TVFA production was also observed for CGP data. As the OLR and SRT increased the CGP in the reactors increased (fig. 1.d). It is well known that in addition to VFAs and alcohols both $\mathrm{H}_{2}$ and $\mathrm{CO}_{2}$ are produced through acidification. However, GC analyses unexpectedly indicated that methane was produced in all of the reactors studied at varied OLRs and SRTs (fig. 1.e). Especially, methane percent of the biogas increased from 5 to $15-27 \%$ when SRTs and OLRs were increased to greater values than 1.25 days and 5 g.VS/L.day, respectively. Although the $\mathrm{pH}$ conditions were close to the optimum operating conditions of highly organic wastes required for acetogenesis. The applied SRT values (1.25 to 4 days) were not favourable for the most sensitive anaerobic bacteria type known as methanogens. The methane production at such low SRTs could be explained by unintentional extended retention times of microorganisms in the reactors due to very high solids concentration and thus lack of homogeneity during daily wasting of sludge. GC analyses also indicated a significant amount of $\mathrm{N}_{2}$ in the biogas of all reactors changing from 35 to $90 \%$ (data was not shown). As expected, denitrication was more dominant at the higher oxidation-reduction potential at the beginning of the experiment. Denitrification might occur during the acidogenic phase, so as to achieve simultaneous VFA production and nitrate elimination, a system could be applied to organic carbon and nitrogen removal from the wastes [23, 29].

Better hydrolysis in acidification process means higher VS reduction. Therefore, in addition to $\mathrm{pH}$ and TVFA production, VS is among the critical parameters in determination of the acidification extent of dairy manure known with its high solids content. The average VS concentrations observed in the reactors at varied SRT and OLR combinations were given in fig. 1.e. It was observed that increasing the OLR and SRT resulted in the VS accumulation. However, due to the continuous feeding and wasting process, such an accumulation may not clearly indicate the possible VS reduction in the reactors. Therefore, a completely stirred tank reactor (CSTR) system modeling was performed to observe the change in the VS content of the reactors at steady-state conditions. In this CSTR model, each reactor was accepted as reactors which were operated under feeding and wasting process without any destruction/degradation of the feeding. For better comparison, percent VS reduction in each reactor was calculated by considering the theoretical and experimental VS concentrations and given in table 2.

In the first part of the study, the effect of solids and hydraulic retention time (SRT/HRT), organic loading rate (OLR) on the acidification degree was investigated. Results indicated that SRT/HRT and OLR of 2 days and 15 g.VS/L.day, respectively, yielded maximum acidification.

The one-phase conventional configuration (R1) was run as the control for the two-phase configuration (R2) in the second part of the study. All reactors started to produce gas production started in the first week of the reactor operation. Gas volumes were measured daily. The results are shown in fig. 2.

The average biogas production values of R1(35), R22(35), R1(25), R22(25) were obtained as $1230 \pm 180,1000 \pm 90,770 \pm 70,290 \pm 50 \mathrm{~mL} /$ day, respectively. Also, a noteworthy gas production of $130 \mathrm{~mL}$ was seen in the mesophilic 
Table 2: $\quad$ The comparison of the reactors with selected parameters.

\begin{tabular}{cccc}
\hline Reactor & VS Reduction $(\%)$ & TVFA $(\mathrm{mg} / \mathrm{L})$ & $\mathrm{pH}$ \\
\hline 1 & 8.4 & 806 & 6.53 \\
2 & 14.5 & 1444 & 6.38 \\
3 & 19.5 & 2236 & 6.29 \\
4 & 0 & 399 & 6.54 \\
5 & 8.9 & 476 & 6.42 \\
6 & 14.8 & 1300 & 6.24 \\
7 & 0 & 412 & 6.57 \\
8 & 0 & 400 & 6.52 \\
9 & 2.3 & 647 & 6.45 \\
\hline
\end{tabular}

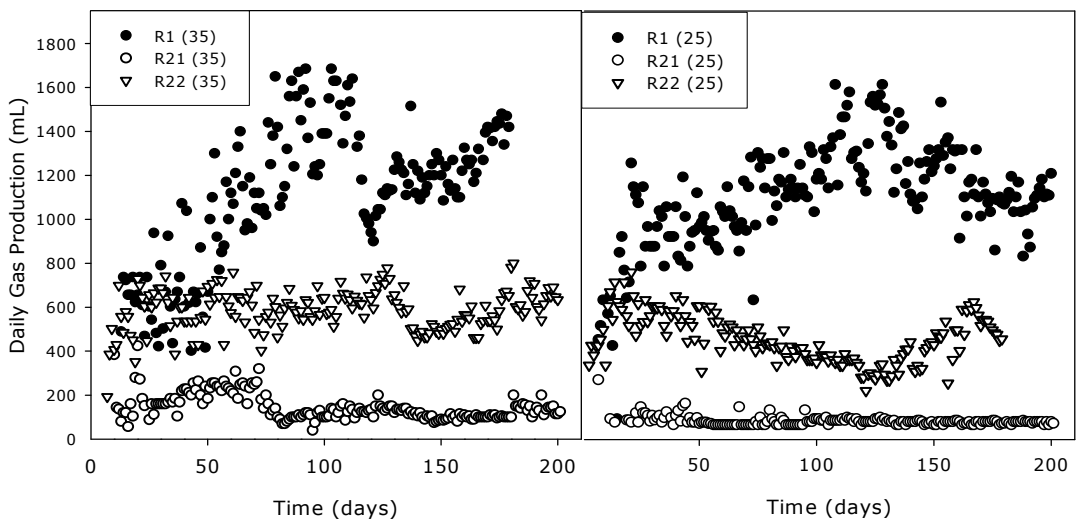

Figure 2: $\quad$ Daily gas productions at $35^{\circ} \mathrm{C}$ and $25^{\circ} \mathrm{C}$.

acidogenic reactor $(\mathrm{R} 21(35))$. There were three different gas production trends in fig. 2. This could be explained by the heterogeneous characteristics of the different manure samples collected at different times. This difference resulted in different biodegradability yields. It is clearly seen that temperature affects the performance of the biogas production (fig. 2). The biogas production increased $60 \%$ when the temperature increased from $25^{\circ} \mathrm{C}$ to $35^{\circ} \mathrm{C}$ in one-phase reactor. These results are very consistent with literature $[24,26]$.

The average methane content of R1(35), R22(35), R1(25), and R22(25) were determined as $63,65,63$, and $43 \%$, respectively. The methane yields of these reactors calculated as $221,216,132,43 \mathrm{~mL} \mathrm{CH}_{4} / \mathrm{g}$.VS added, respectively. The performances of the reactors in terms of biogas yield could be easily comparable with literature values except R22(25) [20, 26].

When the biogas production yields are compared at mesophilic temperature, the performance of two-phase system $\left(216 \mathrm{~mL} \mathrm{CH}_{4} / \mathrm{g}\right.$.VS) is slightly lower than one-phase system $\left(221 \mathrm{~mL} \mathrm{CH}_{4} / \mathrm{g}\right.$.VS) in this study. The earlier experiments with fattening-cattle waste had suggested that a HRT of about 20 days was required at 
$35^{\circ} \mathrm{C}$ for optimum methanogenic anaerobic digestion and that gas production was reduced significantly at 10 days of SRT [24]. Demirer and Chen [5] demonstrated that a conventional one-phase reactor for unscreened dairy manure at a HRT of 20 days produced $0.235 \mathrm{~L}$ biogas/g.VS. When HRT reduced to 10 days, initially an increased was seen in gas production but a few days later an abrupt decline in biogas production were observed, then biogas production was reduced by $90 \%$. In an another work by Wellinger [31] gas yield of straw-rich solid cattle waste was found as 270 and $190 \mathrm{~mL} / \mathrm{g}$.VS at HRT of 20 and 10 days, respectively.

From this above discussion, it is obvious that, the HRT is directly affecting the biogas production. A simple calculation could be reveal which system is preferable in terms of higher biogas production yield. When the HRT of twophase system is increased from 8.6 to 20 days, the system would produce at least $307 \mathrm{~mL} \mathrm{CH}_{4} / \mathrm{g}$.VS instead of $216 \mathrm{~mL} \mathrm{CH}_{4} / \mathrm{g}$.VS by using the literature data for the same substrate $[14,31]$. Thus, gas production in two-phase system (R22(35)) would be $42 \%$ higher than that of the one-phase system (R1(35)). Moreover, a small amount of produced methane from the acid phase (R21) may also be delivered to R22 or directly collected; it is for sure that methane generation of $\mathrm{R} 2$ will also increase.

Volatile solids content are often used as a measure of the biodegradability of the organic fraction of waste. The influent and effluent VS concentrations in the reactors are plotted in fig. 3a. The effluent concentrations revealed a stable trend especially in mesophilic reactors. This stable trend presented that a constant VS reduction occurred throughout the operation. The highest VS conversion was observed with $35-40 \%$ in R1(35) between days 10 and 100 , but during days 100-200 R2(35) had the highest VS reduction with 30-35\%. A $20-30 \%$ VS conversion resulted a wide range in R1(25), this was mainly caused by the operation of this reactor didn't show stability. The VS reduction observed in R2(25) and R21(35) was under 20\% parallel to their gas production and they were very fluctuating. Although both of the systems had the same OLR relative to their inlet concentrations, the inlet concentration of R22 was the effluent concentration of R21 in which there was an average VS reduction of $17 \%$. Therefore, the OLR in R22 was calculated as 2.9 g.VS/L.day. R22(35) had 10$50 \%$ higher VS reduction than R22(25), since the performance of R22(25) was low. The VS reduction in R21(25) was nearly below $10 \%$ at all times.

As VS conversion percentages, effluent SCOD concentrations had also the same trend (fig. 3b). Since the biogas production was due to the degradation of organic compounds. VS and COD parameters could be considered in the same manner as the characteristics of the biodegradability. So, the reduction trends should be similar in terms of VS and COD. The removal of soluble COD concentrations decreased significantly with decreasing temperature. The SCOD reductions of $\mathrm{R} 1(35), \mathrm{R} 2(35), \mathrm{R} 1(25)$ were found as 45, 40, and 55\%, respectively. The amount of sCOD in R21(35), R21(25), and R22(25) were increased 65,25 , and $35 \%$, respectively. The hydrolysis and solubilization of complex materials is the main mechanism in that phase, so that the amount of sCOD increased except R22(25). 


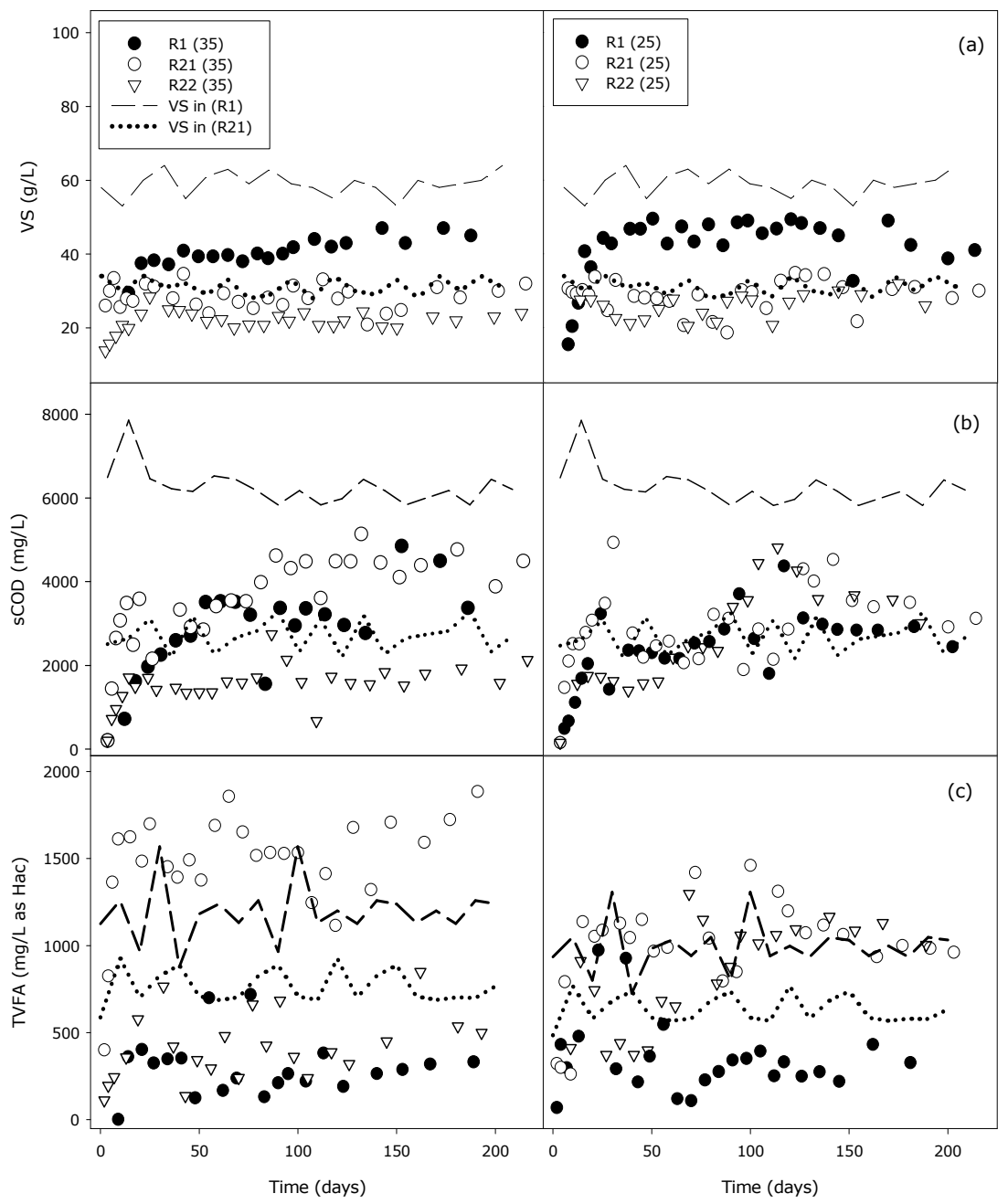

Figure 3: VS, sCOD, and TVFA concentrations in the reactors.

The total volatile fatty acids (as HAc) for runs are displayed in fig. 3c. Acetic acid was the dominating VFA in reactors. The effluents of reactors contained mainly acetic acid, propionic and butyric acids, although higher fatty acids were found at lower concentrations.

The effluent TVFA concentrations of the first-phase reactor at mesophilic and low temperature operated at 2 day HRT increased to 1700 and $1300 \mathrm{mg} / \mathrm{litre}$ (as acetic acid), more than 100 and $60 \%$ increase over that of the influent of R21(35) and R21(25), respectively. The effluent VFA concentration of the second-stage reactor in mesophilic temperature decreased to $350 \mathrm{mg} /$ litre (as acetic acid), but 
the effluent concentration of R22(25) remained the same as expected. The TVFA concentration of R1(25) was much lower than R22(25), since biogas production in R1(25) was more than double of R22(25). This resulted more VFA consumption in R1(25). Acetic acid was also the predominant VFA in the effluent. The acidogenic efficiency could be increased with temperature, but mixing and $\mathrm{pH}$ control were not important parameters [33].

Total effluent VFA value in one-phase reactor was lower than that of the twophase reactor at mesophilic temperature. It does not mean that more VFAs were converted to methane in one-phase reactor, since more VFA transferred from R21(35) to R22(35). Consequently, higher VFA concentration was converted to biogas in two-phase system. In other words the efficiency of two-phase system was higher than one-phase system in terms of VFA consumption.

Anaerobic digestion is a proven technique and at present applied to a variety of waste (water) streams but world wide application is still limited and a large potential energy source is being neglected. Even though several aspects of twophase $\mathrm{AD}$ such as increased stability, lower retention time requirements, liquefaction, etc. are very significant for enhanced $\mathrm{AD}$ of manure until now, its application has been limited to a few studies.

\section{References}

[1] Andrews, J.F. \& Pearson, E.A., Kinetics and characteristics of volatile acid production in anaerobic fermentation process. Internat. J. Air Wat. Poll., 9, pp. 439-469, 1965.

[2] APHA (American Public Health Association), Standard methods for the examination of water and wastewater. 19th Ed., Washington, DC.

[3] Azbar, N. \& Speece, R.E., Two-phase, two-stage, and single-stage anaerobic process comparison. J. Environ. Eng., 127(3), pp. 240-248, 2001.

[4] Demirer, G.N. \& Chen, S., Effect of retention time and organic loading rate on anaerobic acidification and biogasification of dairy manure. J. Chemical Technol. Biotechnol., 79 (12), pp. 1381-1387, 2004.

[5] Demirer, G.N. \& Chen, S., Two-phase anaerobic digestion of unscreened dairy manure. Process Biochemistry, 40(11), pp. 3542-3549, 2005.

[6] El-mashad, H.M., Zeeman, G., Loon, W.K.P. van, Bot, G.P.A. \& Lettinga, G., Anaerobic digestion of solid animal waste in an accumulation system at mesophilic and thermophilic conditions, start up, Water Sci. Technol., 48(4), pp. 217-220, 2003.

[7] Elefsiniotis, P. \& Oldham, W.K., Effect of HRT on acidogenic digestion of primary sludge. J. Env. Eng., 120, pp. 645-660, 1994.

[8] Ghosh, S., Improved Sludge Gasification by Two-Phase Anaerobic Digestion. J. Env. Eng., 113(6), pp. 1265-1284, 1987.

[9] Ghosh, S., Conrad, J.R. \& Klass, D.L., Anaerobic acidogenesis of wastewater sludge. $J W P C F, 47$, pp. 30-45, 1975. 
[10] Ghosh, S., Ombregt, J.P. \& Pipyn, P., Methane production from industrial wastes by two-phase anaerobic digestion. Water Res., 19(9), pp. 10831088, 1985.

[11] Ghosh, S., Buoy, K., Dressel, L., Miller, T., Wilcox, G. \& Loos, D., Pilotand full-scale two-phase anaerobic digestion of municipal sludge. Water Environ. Res., 67(2), pp. 206-214, 1995.

[12] HACH, HACH Water Analysis Handbook, Loveland, HACH Company, second ed.

[13] Han, S.K., Shin, S.H., Song, Y.C., Lee, C.Y. \& Kim, S.H., Novel anaerobic process for the recovery of methane and compost from food waste. Water Sci. Technol., 45(10), pp. 313-319, 2002.

[14] Hobson, P.N. \& Wheatley, A.D., Anaerobic digestion: modern theory and practice, ISBN: 1851669582. Elsevier Applied Science, London, 1993.

[15] Ince O., Performance of a two-phase anaerobic digestion system when treating dairy wastewater. Water Res., 32(9), pp. 2707-2713, 1998.

[16] Ke, S., Shi, Z. \& Fang, H.H.P., Applications of two-phase anaerobic degradation in industrial wastewater treatment. Int. J. Environment and Pollution, 23(1), pp. 65-80, 2005.

[17] Keshtkar, A., Meyssami, B., Abolhamd, G., Ghaforian, H. \& Asadi, M.K., Mathematical modeling of non-ideal mixing continuous flow reactors for anaerobic digestion of cattle manure. Bioresour. Technol., 87, pp. 113-124, 2003.

[18] Kubler, H., \& Schertler, C., Three-phase anaerobic digestion of organic wastes. Water Sci. Technol., 30(12), pp. 367-374, 1994.

[19] Lo, K.V., Liao, P.H., \& Bulley, N.R., Two-Phase Mesophilic anaerobic digestion of screened dairy manure Using Conventional and Fixed-Film Reactors. Agricultural Wastes, 17, pp. 279-291, 1986.

[20] Mackie, R.I. \& Bryant, M.P., Anaerobic digestion of cattle waste at mesophilic and thermophilic temperatures. App. Microbial. Biotechnol., 43, pp. 346-350, 1995.

[21] Nallathambi, G.V., Anaerobic digestion of biomass for methane production: a review. Biomass and Bioenergy, 13(1-2), pp. 83-114, 1967.

[22] Pohland, F.G. \& Ghosh, S., Developments in anaerobic stabilization of organic wastes the two-phase concept. Environ. Lett., 1, pp. 255-66, 1971.

[23] Rustrian, E., Delgenes, J.P., Bernet, N. \& Moletta, R., Simultaneous removal of carbon, nitrogen and phosphorus from wastewater by coupling two-step anaerobic digestion with a sequencing batch reactor. J. Chem. Technol. Biotechnol., 73, pp. 421-431, 1998.

[24] Summers, R., Hobson, N., Harries, C.R. \& Richardson, A.J., Stirred-tank, mesophilic, anaerobic digestion of fattening-cattle wastes and of whole and separated dairy-cattle wastes. Biological Wastes, 20(1), pp. 43-62, 1987.

[25] Sung, S. \& Santha, H., Performance of temperature-phased anaerobic digestion (TPAD) system treating dairy cattle wastes. Water Res., 37, pp. 1628-1636, 2003. 
[26] Varel, V.H., Hashimoto, A.G. \& Chen, Y.R., Effect of temperature and retention time on methane production from beef cattle waste. App. Environ. Microbiol., 40(2), pp. 217-222, 1980.

[27] Verrier, D., Roy, F. \& Albagnac, G., Two-phase methanization of solid vegetable waste. Biological Wastes, 22 pp. 163-177, 1987.

[28] Verstraete, W. \& Vandevivere, P., New and broader applications of anaerobic digestion. Environ. Sci. Technol., 28(2), pp. 151-173, 1999.

[29] Vigneron V, Ponthieu M, Barina G, Audic JM, Duquennoi C, Mazéas L, Bernet N. \& Bouchez, T., Nitrate and nitrite injection during municipal solid waste anaerobic biodegradation. Waste Manag., 27(6), pp. 778-791, 2007.

[30] Wang, J.Y., Xu, H.L., Zhang, H. \& Tay, J.H., Semi-continuous anaerobic digestion of food waste using a hybrid anaerobic solid-liquid bioreactor. Water Sci. Technol., 48(4), pp. 169-174, 2003.

[31] Wellinger, A., Process design of agricultural digesters. Nova Energie $\mathrm{GmbH} \quad$ Elggerstrasse $36 \quad 8356 \quad$ Ettenhausen, Switzerland. http://homepage2.nifty.com/biogas/cnt/refdoc/whrefdoc/d14prdgn.pdf.

[32] Yilmaz, V. \& Demirer, G., Improved anaerobic acidification of unscreened dairy manure. Environ. Eng. Sci., 25(3), pp. 309-317, 2008. 